\title{
Jogos musicais para o desenvolmento e aprendizagem de crianças de 06 a 10 anos
}

\section{Musical games for the development and learning of children from 6 to 10 years old}

\author{
DOI: $10.46814 /$ lajdv3n4-001
}

Recebimento dos originais: 01/052021

Aceitação para publicação: 31/06/2021

Natália Benevenuto de Souza

Pós em Psicopedagogia.

Instituição de atuação atual: Rede Municipal de Ensino - Prefeitura Municipal de Araras

Professora concursada nos cargos: PEB I; PEB II (Arte)

Endereço completo: Rua César Dezotti, 703 - Pedras Preciosas

E-mail: tata_benevenuto@hotmail.com

\section{Guilherme, C.C.F.}

Orientador.

Centro Universitário Hermínio Ometto - UNIARARAS,

E-mail: claudiaguilherme@uniararas.br

\section{INTRODUÇÃO}

O som está presente em nossa vida a todo instante, em diversas ações do dia-a-dia. Quando não o reproduzimos, ao menos o escutamos, ora reproduzido por pessoas ora por um objeto, um veículo, uma máquina. De alguma forma, o Homem sempre esteve à busca da combinação que sons que agradassem aos ouvidos e expressassem emoções, ou seja, a música. Com relação à presença da música na história da humanidade, podemos afirmar que como linguagem sempre esteve presente nas diversas culturas para comunicar sentimentos humanos (COLL; TEBEROSKY, 2004)

Dentre tantas maneiras de se utilizar o som, o fazer musical está em evidência nesta pesquisa. A música está ligada à vivência do indivíduo, à expressão humana e por meio de jogos musicais há possibilidade de promoção de desenvolvimento além da expressividade, mas também pela socialização e integração com diversas áreas do conhecimento humano. Ensinar algo às crianças exige uma metodologia de ensino que as chamem para o aprendizado. Se utilizarmos algo que elas gostam e se identificam para iniciar a atividade ou até mesmo para atingir o objetivo, adiantamos grande parte do seu trabalho de aprendizagem, pois uma das coisas mais difíceis para o profissional é fazer a criança se interessar pela atividade, ainda mais quando ela não sabe ou não entende qual o objetivo daquilo que está fazendo.

Trabalhar jogos musicais com crianças com dificuldades de aprendizagem é uma possibilidade de intervenção do psicopedagogo, e, sem dúvida, um elemento prazeroso, pois sem que a criança 
perceba, algo está sendo introduzido aos conhecimentos dela de maneira lúdica. Não significa que o psicopedagogo deve trabalhar somente jogos musicais, mas que esse momento possa ser trabalhado num determinado momento ao longo do atendimento, seja clínico ou institucional.

\section{OBJETIVO}

Esta pesquisa teve por objetivo discutir a importância dos jogos musicais como possibilidade de melhoria no desenvolvimento e aprendizagem das crianças de 06 a 10 anos. No caso de atendimento institucional psicopedagógico, o trabalho é voltado para as crianças do Ciclo I (do $1^{\circ}$ ao $5^{\circ}$ ano). Realizamos uma pesquisa bibliográfica para encontrar fundamentos desta importância, assim como para fornecer aos professores e, especialmente, psicopedagogos, a possibilidade de utilizar a música como ferramenta de ensino.

\section{REVISÃO DE LITERATURA}

Para jogarmos musicalmente precisamos saber a definição das palavras "jogo" e "música" e posteriormente fazer o elo entre elas. Para Retondar (2004) o jogo é algo muito ligado ao ser humano, é uma espécie de prática dos sonhos, do consciente e até do inconsciente de cada um que o joga. Aquele que joga, o vive e intensamente:

\footnotetext{
O jogo, como fenômeno humano por Excelência, é simbólico, se enreda em uma lógica própria de sentidos. É uma realidade que mapeia, inscreve, situa e projeta no homem ao mundo dos sonhos, desejos e paixões mais íntimas. O jogo é a palavra que não pode ser dita oralmente, que significa profundamente, mas que não é capaz de dizer tudo, pois há sempre alguma coisa a ser dita. É abertura ao mistério, inteligível e ininteligível, tensão permanente, luta incessante entre o imaginário embalado pelo imponderável (RETONDAR, 2004, p.137).
}

Quanto à música, esta, por sua vez é uma arte de manifestar os nossos sentimentos através do som. Fica claro aqui que "música" não tem a mesma definição que "som" e sim que para se fazer uma música utilizamo-nos de vários elementos, dentre eles o som. Para Brito (2003):

\footnotetext{
Música não é melodia, ritmo ou harmonia, ainda que esses elementos estejam muito presentes cotidianamente. Música é também melodia, ritmo, harmonia, dentre outras possibilidades de organização do material sonoro. O que importa, efetivamente, é estarmos sempre próximos da ideia essencial à linguagem musical: criação de formas sonoras com base em som e silêncio (BRITO, 2003, p. 26).
}

Podemos utilizar a música para várias coisas e dentre essa variedade citamos a música como um meio de aprendizagem. O indivíduo canta ou escuta tal música enquanto aprende. Esse tipo de utilização que fazemos com música pode ocorrer tanto dentro como fora da escola, porém quando a praticamos fora do ambiente escolar, entre amigos, na rua, não temos intenção, isto é, não damos 
significado a cada elemento ali inserido, mas isso também nos proporciona a aprendizagem. Já na escola, um ambiente ideal e preparado para obtenção de conhecimento, tal atividade é realizada com intenção educativa a fim de alcançar seus objetivos na sua maior profundidade. No caso das crianças, estas brincam enquanto aprendem e o resultado que se é esperado é trabalhado durante o processo de aprendizagem de forma livre e espontânea.

Para Gainza (apud ALMEIDA e LEVY, 2010) aprender música é um direito do ser humano e que deve ser atendido:

(...) a música é um direito humano, e essa é a primeira razão pela qual deve ser, necessariamente, ensinado na escola. Trata-se de uma linguagem básica para a qual viemos preparados de fábrica: não somente estamos programados para falar e caminhar, mas também para fazer música (GAINZA apud ALMEIDA E LEVY, 2010, p.11).

Todo e qualquer indivíduo é um ser musical e a tal linguagem básica que Gainza (apud ALMEIDA e LEVY, 2010) nos fala é aquela que nos transmitirá o essencial para aflorarmos no futuro. Aprender música na escola não significa que sairemos formados em música ou que seremos um músico erudito ou gênio musical. O que a escola vai fazer é educar o seu aluno musicalmente, assim como nas demais disciplinas, a música será mais uma linguagem. O aluno saberá de seus princípios básicos. Se no futuro essa for área a qual tem habilidade e interesse para explorá-la melhor, o indivíduo poderá dar continuidade. $\mathrm{O}$ que criança necessita como um direito dela é de aprender música, ou melhor, ainda, de aprender por meio da música.

Para Brito (2001) os balbucios, a fala, uma música cantarolada, uma cantiga de roda entre as crianças, uma batucada na mesa, um movimento corporal, dentre outras vivências, são resultados de aprendizagem, pois no ensino da música não aprendemos apenas cantar, como também nos movimentar, tocar e conhecer mais sobre um determinado tema a ser trabalhado por meio de música. Alunos com dificuldade de aprendizagem se destacam quando envolvidos numa das quatro artes (teatro, dança, música e desenho). As atividades musicais trabalham intrinsecamente tanto na área de humanas como na de exatas.

Snyders (2008, p.69) comenta em seu livro a alegria que a música proporciona a todo e qualquer indivíduo, pois "a música possui um caráter patético, apaixonante, ela nos "morde" - e é por isso que ela chega (e frequentemente mesmo as obras mais elaboradas) a se impor a todos, mesmo aqueles que não têm muita familiaridade com ela."

O profissional precisa, de todas as formas, entrar no mundo da criança para que haja o sucesso escolar, pois tudo que obtemos sucesso na nossa vida é devido à maneira como nos foi apresentado. Para Loureiro (2003) para aprender o conceito de número, por exemplo, não necessariamente é preciso giz e lousa, a música pode ajudar. 
Além disso a criança já traz uma bagagem que pode ser aproveitada e ampliada. Estamos diante de crianças que nos chegam carregadas de valores, costumes, culturas. Cada indivíduo traz algo consigo e o vivencia com os demais a sua volta e assim vai se moldando, se desenvolvendo. É neste momento em que o profissional intervém, possibilitando momentos favoráveis para o desenvolvimento e aprendizagem da criança. O estímulo é um dos instrumentos, que percorre todo o processo de aprendizagem e quem o fornece ao aluno é o professor e/ou psicopedagogo. Cabe ao profissional ter esse manejo no seu trabalho. Snyders (2008, p.18) diz que "é preciso que os esforços dos alunos sejam estimulados, compensados e recompensados por uma alegria que possa ser vivida no momento presente". O que muito nos preocupa é que nossas crianças trazem para o ambiente escolar a ideia de que a alegria acontece sempre em espaços fora do ambiente escolar, em momentos livres, sem o compromisso de aprendizagem.

Toda disciplina tem condições de trazer para a sala de aula a alegria capaz de dar significado a cada conhecimento novo na ótica de Snyders (2008). Se tal alegria (combinada com ludicidade) não é promovida em nossos alunos, estes, por sua vez, a procurarão em outro ambiente. Sabemos que essa tarefa não é fácil e que demanda tempo para se alcançá-la, porém é preciso, tanto o profissional quanto aquele que aprende manter viva a ideia de que a alegria não está somente inserida em ambiente extraescolar.

Em qualquer conhecimento a ser transmitido há um objetivo e este precisa ser o alicerce para das atividades realizadas em ambiente escolar, pois a pessoa que ensina com o alicerce, dá significado aquele que aprende. Segundo Gainza (1988) vale ressaltar que a escola é um lugar no qual, além de aprender, se troca experiência, acontece o encontro e de alguma forma a expressão faz-se necessária, colocando-se em evidência. O significado do que se ensina se responde por meio da obra-prima ${ }^{1}$ a qual se constitui com a experiência, a práxis.

Não há receitas prontas para nossos profissionais até mesmo porque o indivíduo é único, possui suas próprias características que as diferenciam dos demais. Portanto, uma receita pronta e acabada pode provavelmente satisfazer a sede de conhecimento de apenas alguns dentre tantos que desejam saciá-la.

O trabalho de educar musicalmente nossas crianças se constitui a partir de sonhos, reflexões do nosso ensino, de cabeças pensantes e com o mesmo objetivo a ser desenvolvido. Não basta o profissional estar cercado dos demais colegas de trabalho que pensam o contrário, que não fazem questão de trazer para a vivência o significado daquilo que o faz e somente ele pensar dessa forma, pois em contato com esses "profissionais" a criança desconstrói, muitas vezes, tudo aquilo que pouco a pouco fora construído. A alegria proporcionada aos alunos necessita de todos os profissionais em prol dela. O que vemos ainda nos dias de hoje é basicamente um ensino sem inovação, sem criatividade 
e sem desempenho para melhor passar o conhecimento adiante. A música está aí e não é sugada pelos que a utilizam, é apenas executada de forma superficial, estética.

A criança com dificuldade de aprendizagem, além de carregar tal peso, provavelmente não vivenciou momentos de alegria no ambiente escolar. Pode até ser que alcançou algum estágio de alegria, mas no ambiente extraescolar. Quando chega à escola é como se apagasse o mundo que vive para o lado de fora da escola. Coloca um pensamento negativo em evidência de que o compromisso jamais pode proporcionar a alegria. Essa criança pode ter dificuldade na resolução de problemas. $\mathrm{O}$ professor na sala de aula continua somente com o giz, saliva e lousa. A criança lê e relê diversas vezes o mesmo problema. De tanto ler começa a pensar no mundo lá fora, nos momentos os quais se alegrou sem muito esforço. E neste momento uma ideia infeliz diz a ela: "Em que mundo você vive?". Essa é a voz real, aquela em que não se precisa esfregar as mãos nos olhos para acordar, é tristeza ali cercada, sem perspectivas de aprendizagem. Isso muito nos preocupa, porque ainda há vestígios de falas desse tipo.

Atividades que envolvem jogos musicais, especialmente brincadeiras cantadas e jogos rítmicos podem auxiliar especialistas, como psicopedagogos a resolverem parte dos problemas de atenção e aprendizagem. A pergunta colocada no início dessa conversa tem possibilidade de ser atendida, ou seja, a escola pode ensinar as alegrias da música, como diz Snyders (2008).

Segundo Chiarelli e Barreto (2005):

As atividades de musicalização permitem que a criança conheça melhor a si mesma, desenvolvendo sua noção de esquema corporal, e também permitem a comunicação com o outro. Weigel (1988) e Barreto (2000) afirmam que atividades podem contribuir de maneira indelével como reforço no desenvolvimento cognitivo/ linguístico, psicomotor e sócio-afetivo da criança. (CHIARELLI e BARRETO, 2005, p. 3)

\section{CONSIDERAÇÕES FINAIS OU PROPOSIÇÃO}

Conclui-se com esta pesquisa que os jogos musicais são atividades as quais possibilitam a melhoria no desenvolvimento e aprendizagem das crianças. O profissional precisa, ao menos, estar atento quanto a sua atuação perante as dificuldades apresentadas pelos seus próprios alunos.

Vimos também a importância do estímulo contínuo, uma vez que as crianças nos chegam com pouco entusiasmo para o ambiente escolar, mesmo que no extraescolar aprendem constantemente e de forma livre.

Há um problema quanto à renovação metodológica em nossas escolas e a música pode servir tanto para propiciar momentos mais alegres e prazerosos, como também contribuir para uma aprendizagem integrada, interdisciplinar e com mais sentido para criança. No caso que estudamos, 
buscou-se também analisar a possibilidade de trabalho psicopedagógico com a música, mas sempre visando auxiliar na questão das aprendizagens e torna-las mais lúdicas e significativas às crianças.

Palavras-Chave: ensino de música; desenvolvimento e aprendizagem; jogos musicais. 


\section{REFERÊNCIAS BIBLIOGRÁFICAS \\ REFERENCIAS BIBLIOGRÁTICAS}

ALMEIDA, B. e LEVY, G. O livro de brincadeiras musicais da Palavra Cantada. São Paulo: Melhoramentos, 2010.

BRITO, T. A. A música da criança. IN: Avisa lá. Publicação Trimestral do Instituto Avisa Lá. Ano IV, $\mathrm{n}^{\mathrm{o}} 15$, julho de $2003^{\mathrm{a}}$ (pp.- 7 - 17) Peirópolis, 2001.

Koellreutter educador: O humano como objetivo da Educação Musical. São Paulo:

CHIARELLI L. K. M. e BARRETO. S. J. A música como meio de desenvolver a inteligência e a integração do ser. Revista Reacrearte, n. 3, Junho de 2005. Disponível em: http://www.iacat.com/revista/recrearte/recrearte03/musicoterapia.htm Acesso em Maio de 2015.

GAINZA, V. H. Estudos de Psicopedagogia musical. São Paulo: Summus, 1988.

LOUREIRO, A. M. A. O ensino da música na escola fundamental. Campinas. SP: Papirus, 2003.

RETONDAR, J. J. M. A produção imaginária de jogadores compulsivos: a poética do espaço do jogo. São Paulo. Ed. Vetor, 2004.

SNYDERS, G. A escola pode ensinar as alegrias da música. 5a Ed. São Paulo: Cortez, 2008. 